\title{
FATWA EKONOMI SYARIAH DI INDONESIA
}

\author{
Anita Marwing \\ Fakultas Syariah Institut Agama Islam Negeri Palopo \\ Email : nithara2@gmail.com
}

\begin{abstract}
This article aims to review the fatwa concerning sharia economics in Indonesia which includes the method and process of establishing a fatwa on sharia economics and fatwa on sharia economics issued by the National Sharia Council of the Indonesian Ulema Council. This institution has the duty to explore, study, formulate the values and principles of Islamic law (syariah) to be used as guidelines in transaction activities in Islamic financial institutions, as well as oversee their implementation and implementation. This guideline is then poured in the form of fatwa by paying attention to the general welfare and maqashid syari'ah so that the fatwa can truly answer the problems that arise in the community and can truly be an alternative that can be used as a guide in running a sharia economic business in Indonesia.
\end{abstract}

Keywords : Fatwa, Syariah Economic, DSN-MUI

\begin{abstract}
Abstrak
Artikel ini bertujuan untuk mengkaji fatwa mengenai ekonomi syariah di Indonesia yang meliputi metode dan proses penetapan fatwa tentang ekonomi syariah serta fatwafatwa mengenai ekonomi syariah yang dikeluarkan oleh lembaga Dewan Syariah Nasional Majelis Ulama Indonesia. Lembaga ini bertugas untuk menggali, mengkaji, merumuskan nilai dan prinsip-prinsip hukum Islam (syari'ah) untuk dijadikan pedoman dalam kegiatan transaksi di lembaga-lembaga keuangan syariah, serta mengawasi pelaksanaan dan implementasinya. Pedoman inilah yang kemudian dituangkan dalam bentuk fatwa dengan memperhatikan kemaslahatan umum dan maqashid syari'ah sehingga fatwa tersebut benar-benar dapat menjawab permasalahan yang timbul di kalangan masyarakat dan benar-benar dapat menjadi alternatif yang dapat dijadikan pedoman dalam menjalankan bisnis ekonomi syariah di Indonesia.
\end{abstract}

Kata Kunci: Fatwa, Ekonomi Syariah, DSN-MUI

\section{PENDAHULUAN}

Ekonomi syariah adalah kumpulan norma hukum yang bersumber dari al-Qur'an dan al-Hadis yang mengatur per-ekonomian umat manusia. ${ }^{1}$ Oleh sebab itu, ekonomi syariah dimaknai lebih luas men-cakupi semua aktivitas manusia untuk mem-

${ }^{1}$ Zainuddin Ali, Hukum Ekonomi Syariah (Jakarta: Sinar Grafika, 2008), h. 4. 
pertahankan kehidupannya yang meliputi semua usaha, kegiatan, jasa dan profesi sepanjang tidak bertentangan dengan al-Qur'an dan as-Sunnah, semuanya juga sudah termasuk dalam makna ekonomi syari'ah. ${ }^{2}$

Ekonomi syariah berbeda dari kapi-talisme, sosialisme, maupun Negara kesejah teraan (welfare state). Berbeda dari kapi-talisme karena Islam menentang eksploitasi oleh pemilik modal terhadap buruh yang miskin, dan melarang penumpukan kekayaan. Selain itu, ekonomi dalam kaca mata Islam merupakan tuntutan kehidupan sekaligus anjuran yang memiliki dimensi ibadah.

Perkembangan ekonomi syari'ah di Indonesia demikian cepat, khususnya per bankan, asuransi dan pasar modal. Ber-dasarkan data statistik Perbankan Syariah BI bulan April 2015, pencapaian perbankan syariah terus mengalami peningkatan. Dalam delapan tahun terakhir (2007-2015), lonjakan pertumbuhan perbankan syari'ah mengalami peningkatan yang signifikan. Jumlah Bank Umum Syariah (BUS) pada tahun 2007 hanya 3 unit dengan jumlah kantor 401 unit saat ini mencapai 12 unit dengan jumlah kantor 2.135 unit. Jumlah unit usaha syari'ah pada April 2015 berjumlah 23 dengan jumlah kantor 323 unit. Ditambah lagi, pada tahun 2007 jumlah BPRS 114 unit dengan jumlah kantor 185 unit saat ini jumlah BPRS mencapai 162 unit dengan jumlah kantor 433 unit dan total jumlah kantor Syari'ah sebanyak 2.891 unit. Secara geografis, sebaran jaringan kantor perbankan Syariah juga telah menjangkau masyarakat di lebih 89 kabupaten/kota di 33 provinsi. $^{3}$

Di luar sektor perbankan, bidang-bidang garapan lembaga keuangan syari'ah lainnya juga memberikan tren pertumbuhan dan perkembangan yang cukup positif. Di bidang asuransi misalnya dimulai dengan dua anak perusahaan PT. Asuransi Takaful Indonesia, yaitu PT. Asuransi Takaful Ke-luarga yang berdiri pada tanggal 25 Agustus

${ }^{2}$ Lihat M. Arfin Hamid, Ekonomi Syari'ah Sebagai Kebutuhan, Pidato Pengukuhan Guru Besar dalam Bidang Ilmu Hukum pada Fakultas Hukum Universitas Hasanuddin (Makassar: Universitas Hasanuddin, 2013), h. 29.

${ }^{3}$ Bank Indonesia, Statistik Perbankan Syari'ah, www.bi.go.id, diakses tanggal 25 November 2015. 
1994 dan PT. Asuransi Takaful Umum yang berdiri pada tanggal 2 Juni 1995, perasuransian syari'ah terus berkembang. ${ }^{4}$

Berdasarkan Laporan Perkembangan Perbankan Syari'ah Bank Indonesia tahun 2012, jumlah perusahaan asuransi syari'ah mencapai 45 perusahaan, yang terdiri dari 3 buah perusahaan asuransi jiwa syari'ah, 2 buah perusahaan asuransi kerugian syari'ah, 17 unit syari'ah perusahaan kerugian, dan 3 unit syari'ah perusahaan reasuransi. ${ }^{5}$ Di bidang bisnis pembiayaan, beberapa peru-sahaan pembiayaan mulai menjalankan kegiatan pembiayaan berdasarkan prinsip syari'ah. Dimulai dengan 2 buah perusahaan yang murni syari'ah dan 2 buah perusahaan yang mempunyai unit usaha syari'ah pada tahun 2008 sampai dengan akhir 2012 tercatat jumlah perusahaan pembiayaan yang melakukan kegiatan pembiayaan berdasar-kan prinsip syari'ah di bawah pengawasan Bapepam-LK adalah sebanyak 35 perusa-haan, meningkat dari tahun 2011 yang ber-jumlah 14 perusahaan. Demikian pula obli-gasi syari'ah yang tumbuh pesat meng-imbangi asuransi dan perbankan syari'ah. ${ }^{6}$

Para praktisi ekonomi syari'ah, mas-yarakat dan pemerintah (regulator) membutuhkan fatwa-fatwa syariah dari lembaga ulama (MUI) berkaitan dengan praktek dan produk di lembaga-lembaga keuangan syar-iah tersebut. Perkembangan lembaga keuan-gan syariah yang demikian cepat harus diimbangi dengan fatwa-fatwa hukum syari'ah yang valid dan akurat, agar seluruh produknya memiliki landasan yang kuat secara syari'ah. Untuk itulah Dewan Syari'ah Nasional (DSN) dilahirkan pada tahun 1999 sebagai bagian dari Majlis Ulama Indonesia. Masalah ekonomi syariah merupakan wewenang Peradilan Agama yang diatur dalam Undang-Undang RI Nomor 3 Tahun 2006 tentang Perubahan atas Undang-Undang Nomor 7 Tahun 1989 tentang Peradilan Agama.

Dalam sistem hukum Islam, fatwa mempunyai peranan yang cukup dominan dalam memberikan pertimbangan hukum keagamaan kepada masyarakat sekalipun

\footnotetext{
${ }^{4}$ Tim Penyusun, Majalah Peradilan Agama, Edisi III, Mei 2013, h. 9.

${ }^{5}$ Bank Indonesia, Statistik Perbankan Syari'ah, www.bi.go.id, diakses tanggal 25 November 2015. ${ }^{6}$ Lihat Majalah Peradilan Agama, Edisi III, Mei 2013, h. 8-9.
} 
fatwa tidak mempunyai kekuatan hukum yang mengikat. Namun, dalam konteks masyarakat Indonesia, status fatwa lembaga keagamaan khususnya fatwa Majelis Ulama Indonesia mempunyai pengaruh yang tidak kecil. Contoh, yang dapat dilihat yaitu ketika dikeluarkannya fatwa MUI tentang ke-haraman bunga bank pada tahun 2003 ter-nyata mendapat respon masyarakat yang mempunyai efek cukup signifikan dalam kehidupan masyarakat.

Hal ini menunjukkan bahwa fatwa Majelis Ulama Indonesia memberikan pengaruh pada tatanan sosial kemasyarakatan bangsa Indonesia secara keseluruhan. Fakta tersebut menunjukkan bahwa fatwa MUI memiliki peran penting di dalam masyarakat meskipun fatwa MUI tidak mengikat secara hukum, tetapi prakteknya sering dijadikan rujukan oleh masyarakat. Kuatnya pengaruh fatwa MUI tersebut, menyebabkan MUI harus lebih responsif atas dinamika yang ada dalam kehidupan masyarakat sehingga fatwa yang dikeluarkan sejalan dengan kemas-lahatan. Oleh sebab itu, maka penting untuk dilakukan kajian tentang fatwa ekonomi syariah di Indonesia yang melingkupi meto-de yang digunakan dalam menetapkan fatwa tentang ekonomi syariah.

\section{KONSEPSI FATWA}

Fatwa (الفتوى) menurut bahasa berarti jawaban mengenai jawaban suatu kejadian atau peristiwa (memberikan jawaban yang tegas terhadap segala peristiwa yang terjadi dalam masyarakat). ${ }^{7}$ Menurut imam Zamak hsyari dalam bukunya al-Kasyaf pengertian fatwa adalah suatu jalan yang lempeng atau lurus. ${ }^{8}$ Dalam ilmu Ushul Fiqh, fatwa berarti pendapat yang dikemukakan seorang muj-tahid atau faqih sebagai jawaban yang diaju-kan peminta fatwa dalam suatu kasus yang sifatnya tidak mengikat. ${ }^{9}$ Adapula yang mengartikan kata fatwa dalam 2 versi yaitu:

\section{h. 5 .}

${ }^{7}$ Yusuf Qardhawi, Fatwa antara Ketelitian dan Kecerobohan (Jakarta: Gema Insani Press, 1997),

${ }^{8}$ Rohadi Abdul Fatah, Analisis Fatwa Keagamaan dalam Fiqih Islam (Jakarta: PT. Bumi Aksara, 2006), h.7.

${ }^{9}$ Abdul Aziz Dahlan, et.al., Ensiklopedi Hukum Islam, Jilid I (Jakarta: Ichtiar Baru van Hoeve, 1996), h. 326. 
1. Fatwa: (keputusan, pendapat) yang diberikan oleh mufti tentang suatu masalah.

2. Fatwa: nasehat orang alim, pelajaran baik, petuah. ${ }^{10}$

Fatwa menurut Prof. Amir Syari-fuddin, berasal dari kata afta yang berarti memberikan penjelasan. Secara defenitif, fatwa yaitu usaha memberikan penjelasan tentang hukum syara’ oleh ahlinya kepada orang yang belum mengetahuinya. ${ }^{11}$

Sedangkan fatwa menurut arti syariat adalah suatu penjelasan hukum syariat dalam menjawab suatu perkara yang diaju-kan oleh seseorang yang bertanya, baik penjelasan itu jelas atau ragu-ragu dan pen-jelasan itu mengarah pada dua kepentingan, yakni kepentingan pribadi atau kepentingan masyarakat banyak. ${ }^{12}$

Namun ada sebagian fuqaha yang menyatakan bahwa "fatwa" adalah bahasa arab yang berarti "jawaban pertanyaan" atau "hasil ijtihad" atau "ketetapan hukum", maksudnya ialah ketetapan atau keputusan hukum tentang suatu masalah atau peristiwa yang dinyatakan oleh seseorang mujtahid sebagai hasil ijtihadnya.

Dilihat dari produk hukum, terdapat perbedaan antara mujtahid dan mufti, para mujtahid mengistinbathkan (menyimpulkan) hukum dari al-Qur'an dan sunnah dalam berbagai kasus, baik diminta oleh pihak lain maupun tidak. Adapun mufti tidak mengeluarkan fatwanya, kecuali apabila diminta dan persoalan yang diajukan kepadanya adalah persoalan yang bisa dijawab sesuai dengan pengetahuannya. Oleh sebab itu, mufti dalam menghadapi suatu persoalan hukum harus benar-benar mengetahui secara rinci kasus yang dipertanyakan, mempertim-bangkan kemaslahatan peminta fatwa, ling-kungan yang mengitarinya, serta tujuan yang ingin dicapai dari fatwa tersebut.

Dari uraian di atas, dapat diketahui hakikat dan ciri-ciri berfatwa sebagai berikut:

1. Ia adalah usaha memberikan pen-jelasan.

2. Penjelasan yang diberikan itu adalah tentang hukum syara' yang diperoleh melalui hasil ijtihad.

\footnotetext{
${ }^{10}$ Depdikbud, Kamus Besar Bahasa Indonesia (Jakarta: Balai Pustaka, 1997), h. 275.

${ }^{11}$ Amir Syarifuddin, Ushul Fiqih (Jakarta: Kencana, 2009), h. 429.

${ }^{12}$ Ibid.
} 
3. Yang memberikan penjelasan itu adalah orang yang ahli dalam bidang yang dijelaskannya itu.

4. Penjelasan itu diberikan kepada orang yang bertanya yang belum menge-tahui hukumnya. ${ }^{13}$

\section{METODE DAN PROSES PENETAPAN FATWA TENTANG EKONOMI SYARIAH}

Pencarian jawaban atas permasalahan baru yang belum tercover dalam al-Qur'an dan Hadis melalui kegiatan ijtihad mem-butuhkan keterampilan dan persyaratan yang ketat. Kegiatan ijtihad hanya dapat dilaku-kan oleh orang-orang yang telah memenuhi syarat dan kriteria tertentu.

Ketatnya syarat dan kriteria untuk dapat melakukan ijtihad, maka tidak memungkinkan semua orang dapat melakukan ijtihad sehingga harus mengikuti pendapat para ahli (ulama). Dalam hal ini, termasuk meminta pendapat atau penjelasan kepada orang yang mempunyai kompetensi dalam menjawab atau memberikan status hukum permasalahan yang dihadapi. Dalam meng-hadapi tuntutan kebutuhan masyarakat dan persaingan bisnis, lembaga perbankan dan keuangan syariah memerlukan produkproduk yang inovatif. Untuk itu, dibutuhkan fatwa syariah dan regulasi yang mendukung penerapan produk yang inovatif tersebut.

Dalam penetapan fatwa, keberadaan metode yang digunakan adalah sangat penting sehingga setiap proses penetapan fatwa harus mengikuti metode tersebut. Sebuah fatwa yang ditetapkan tanpa meng-gunakan metodologi, keputusan hukum yang dihasilkan kurang mempunyai argumentasi yang kokoh. Oleh karenanya, implementasi metode (manhaj) dalam setiap proses pene-tapan fatwa merupakan suatu keniscayaan. ${ }^{14}$

\footnotetext{
${ }^{13}$ Ibid.

${ }^{14}$ Lihat Ma'ruf Amin, Fatwa Dalam Sistem Hukum Islam (Cet. I; Jakarta: eLSAS, 2008), h. 267.
} 
Adapun tahapan dalam penetapan fatwa secara umum dapat dilihat sebagai berikut:

1. Sebelum fatwa ditetapkan hendaklah ditinjau lebih dahulu pendapat para imam mazhab tentang masalah yang akan difatwakan tersebut, secara seksama beserta dalil-dalilnya.

2. Masalah yang telah jelas hukumnya (al-ahkam al-qath'iyyat) hendaklah disam-paikan sebagaimana adanya.

3. Dalam masalah yang terjadi khilafiyah dikalangan mazhab maka:

a. Penetapan fatwa didasarkan pada hasil usaha penemuan titik temu diantara pendapat-pendapat para mazhab melalui metode al-jam 'u wa al-taufiq; dan jika penemuan uaha titik temu tidak berhasil di-lakukan, penetapan fatwa didasar-kan pada hasil tarjih melalui meto-de muqaranah al mazahib dengan menggunakan kaidah ushul fiqh muqaran.

b. Dalam masalah yang tidak ditemu-kan pendapat hukumnya di kala-ngan mazhab, penetapan fatwa di-dasarkan pada hasil ijtihad jama'i (kolektif melalui metode bayani, ta'lili, qiyasi, istihsani ilhaqi) istilahi dan saad aldzari'ah.

c. Penetapan fatwa harus senantiasa memperhatikan kemaslahatan umum (mashalih 'ammah) dan muqasyid al-syari'ah.

Penetapan fatwa tentang ekonomi syariah di Indonesia menjadi otoritas Dewan Syariah Nasional Majelis Ulama Indonesia yang dilakukan melalui rapat pleno yang dihadiri oleh semua anggota Dewan Syariah Nasional-Majelis Ulama Indonesia (DSN MUI) yang terdiri dari para ahli syariah dan ahli ekonomi/keuangan yang mempunyai wawasan syariah serta melibatkan lembaga mitra seperti Bank Indonesia atau lembaga otoritas keuangan lainnya dan pelaku usaha baik perbankan, asuransi, pasar modal, maupun lainnya.

Metode yang digunakan oleh komisi fatwa MUI dalam proses penetapan fatwa melalui 3 pendekatan, yaitu sebagai berikut: 
1. Pendekatan qath'i, yaitu pendekatan qath'i dilakukan dengan berpegang dengan nash al-Qur'an dan Hadis untuk sesuatu masalah apabila masalah yang ditetapkan terdapat dalam nash al-Qur'an ataupun al-Hadis secara jelas.

2. Pendekatan qauli, yaitu pendekatan dalam proses penetapan fatwa dengan mendasarkannya pada pendapat para imam mazhab dalam kitab-kitab fikih terkemuka (al-kutub al-mu'tabarah). ${ }^{15}$ Pendekatan ini dilakukan apabila jawa-ban dapat dicukupi oleh pendapat dalam kitab-kitab fikih terkemuka.

3. Pendekatan manhaji, yaitu pendekatan dalam proses penetapan fatwa yang mempergunakan kaidah-kaidah pokok (al-qawaid al-ushuliyyah) dan metodologi yang dikembangkan oleh imam mazhab dalam merumuskan suatu masalah. Pendekatan manhaji dilakukan melalui ijtihad secara kolektif (ijtihad jama'i), dengan menggunakan metode: mempertemukan pendapat yang berbeda (al-jam'u wat taufiq), memilih pendapat yang lebih kuat dalilnya (tarjih), menganalogikan permasalahan yang muncul dengan permasalahan yang telah ditetapkan hukumnya dalam kitab-kitab fikih (ilhaqi), dan istinbati yaitu metode yang digunakan ketika tidak bisa dilakukan dengan metode ilhaqi karena tidak ada padanan pendapat (mulhaq bih) dalam al-kutub almu'tabarah. Metode istinbati dilaku-kan dengan memberlakukan metode qiyas, istihsan, saad al-dzari'ah. ${ }^{16}$

Secara umum, dalam menetapkan fatwa, DSN-MUI selalu memperhatikan kemaslahatan umum dan maqashid syari'ah sehingga fatwa DSN-MUI benar-benar dapat menjawab permasalahan yang timbul di kalangan masyarakat dan benar-benar dapat menjadi alternatif yang dapat dijadikan pedoman dalam menjalankan bisnis ekonomi syariah di Indonesia. Adapun alur penetapan fatwa tentang ekonomi syariah adalah sebagai berikut:

\footnotetext{
${ }^{15}$ Mardani, Hukum Ekonomi Syariah di Indonesia (Bandung: PT. Refika Aditama, 2011), h. 222.

${ }^{16}$ Ibid., h. 223. Lihat juga Ma'ruf Amin, Op.Cit., h. 268-271.
} 
1. Badan Pelaksana Harian DSN-MUI menerima usulan atau pertanyaan hukum mengenai suatu produk lembaga keu-angan syariah. Usulan atau pertanyaan hukum ini bisa dilakukan oleh praktisi lembaga perekonomian melalui Dewan Pengawas Syariah atau langsung dituju-kan pada sekretariat Badan Pelaksana Harian DSN-MUI.

2. Sekretariat yang dipimpin oleh sekre-taris paling lambat satu hari kerja setelah menerima usulan/pertanyaan harus me-nyampaikan permasalahan kepada ketua.

3. Ketua Badan Pelaksana Harian DSN-MUI bersama anggota BPH DSN-MUI dan staff ahli selambat-lambat-nya 20 hari kerja harus membuat memorandum khusus yang berisi telaah dan pemba-hasan terhadap suatu pertanyaan atau usulan hukum tersebut.

4. Ketua Badan Pelaksana Harian DSN-MUI selanjutnya membawa hasil pembahasan ke dalam rapat pleno Dewan Syariah Nasional MUI untuk mendapat pengesahan.

5. Memorandum yang sudah mendapat pengesahan dari rapat pleno DSN-MUI ditetapkan menjadi fatwa DSN-MUI. Fatwa tersebut ditandatangani oleh ketua DSN-MUI (ex officio Ketua Umum MUI) dan sekretaris DSN-MUI (ex officio Sekretaris Umum MUI). ${ }^{17}$

Fatwa yang dikeluarkan DSN-MUI menjadi rujukan yang mengikat bagi lembaga-lembaga keuangan syariah (LKS) yang ada di Indonesia serta mengikat masyarakat yang berinteraksi dengan LKS.

\section{FATWA-FATWA TENTANG EKONOMI SYARIAH}

Saat ini terdapat 86 fatwa Dewan Syariah Nasional (DSN) Majelis Ulama Indonesia (MUI) seputar Keuangan dan Perbankan Syariah. Hal ini dapat dilihat sebagai berikut:

\footnotetext{
${ }^{17}$ Ibid., h. 275.
} 
1. Fatwa tentang Simpanan
a. Fatwa No. 1: Giro
b. Fatwa No. 2: Tabungan
c. Fatwa No. 3: Deposito

2. Fatwa tentang Mudharabah
a. Fatwa No. 7: Pembiayaan Mudha-rabah (Qiradh)
b. Fatwa No. 38: Sertifikat Investasi Mudharabah Antar bank (Sertifikat IMA)
c. Fatwa No. 50: Akad Mudharabah Musytarakah

3. Fatwa tentang Musyarakah
a. Fatwa No. 8 : Pembiayaan Musya-rakah
b. Fatwa No. 55: Pembiayaan Reke-ning Koran Syariah Musyarakah
c. Fatwa No. 73: Musyarakah Mutana-qisah

4. Fatwa tentang Murabahah
a. Fatwa No. 4: Murabahah
b. Fatwa No. 13: Uang Muka Mura-bahah
c. Fatwa No. 16: Diskon dalam Mura-bahah
d. Fatwa No. 23: Potongan Pelunasan dalam Murabahah
e. Fatwa No. 46: Potongan Tagihan Murabahah (Khashm fi al-Mura-bahah
f. Fatwa No. 47: Penyelesaian Piutang Murabahah bagi Nasabah Tidak Mampu Membayar
g. Fatwa No. 48: Penjadualan Kembali Tagihan Murabahah
h. Fatwa No. 49: Konversi Akad Murabahah
i. Fatwa No. 84: Metode Pengakuan Keuntungan al-Tamwil bi al-Mura-bahah (Pembiayaan Murabahah) di Lembaga Keuangan Syariah
j. Fatwa No. 90 : Pengalihan Pem-biayaan Murabahah antar Lembaga Keuangan Syariah (LKS)

5. Fatwa tentang Salam dan Istishna'
a. Fatwa No. 5: Jual Beli Salam
b. Fatwa No. 6: Jual Beli Istishna' 
c. Fatwa No. 22: Jual Beli Istishna' Paralel

6. Fatwa tentang Ijarah
a. Fatwa No. 9: Pembiayaan Ijarah
b. Fatwa No. 27: Al-Ijarah al-Munta-hiyah bi al-Tamlik (IMBT)
c. Fatwa No. 56: Ketentuan Review Ujrah pada LKS

7. Fatwa tentang Hutang dan Piutang
a. Fatwa No. 19: Qardh
b. Fatwa No. 17: Sanksi atas Nasabah Mampu yang Menunda Pembayaran
c. Fatwa No. 31: Pengalihan Hutang
d. Fatwa No. 67: Anjak Piutang Sya-riah
e. Fatwa No. 79: Qardh dengan Meng-gunakan Dana Nasabah

8. Fatwa tentang Hawalah
a. Fatwa No. 12: Hawalah
b. Fatwa No. 58: Hawalah bil Ujrah

9. Fatwa tentang Rahn (Gadai)
a. Fatwa No. 25: Rahn
b. Fatwa No. 26: Rahn Emas
c. Fatwa No. 68: Rahn Tasjiliy

10. Fatwa tentang Sertifikat Bank Indonesia
a. Fatwa No. 36: Sertifikat Wadiah Bank Indonesia (SWBI)
b. Fatwa No. 63: Sertifikat Bank Indonesia Syariah
c. Fatwa No. 64: Sertifikat Bank Indonesia Syariah Ju'alah

11. Fatwa tentang Kartu (Card)
a. Fatwa No. 42 : Syariah Charge Card
b. Fatwa No. 54 : Syariah Card

12. Fatwa tentang Pasar Uang
a. Fatwa No. 28: Jual Beli Mata Uang (al-Sharf)
b. Fatwa No. 37: Pasar Uang Antar-bank Berdasarkan Prinsip Syariah 
c. Fatwa No. 78: Mekanisme dan Ins-trumen Pasar Uang Antarbank Ber-dasarkan Prinsip Syariah

13. Fatwa tentang Asuransi Syariah

a. Fatwa No. 21: Pedoman Umum Asuransi Syariah

b. Fatwa No. 39: Asuransi Haji

c. Fatwa No. 51: Akad Mudharabah Musytarakah pada Asuransi Syariah

d. Fatwa No. 52: Akad Wakalah bil Ujrah pada Asuransi Syariah dan Reasuransi Syariah

e. Fatwa No. 53: Akad Tabarru' pada Asuransi Syariah

f. Fatwa No. 81: Pengembalian Dana Tabarru' bagi Peserta Asuransi yang Berhenti Sebelum Masa Perjanjian Berakhir

14. Fatwa tentang Pasar Modal Syariah

a. Fatwa No. 20: Pedoman Pelaksa-naan Investasi untuk Reksadana Syariah

b. Fatwa No. 40: Pasar Modal \& Pedoman Umum Penerapan Prinsip Syariah di Bidang Pasar Modal

c. Fatwa No. 65: Hak Memesan Efek Terlebih Dahulu (HMETD) Syariah Fatwa No. 66: Waran Syariah

d. Fatwa No. 80: Penerapan Prinsip Syariah dalam Mekanisme Perdagangan Efek Bersifat Ekuitas di Pasar Reguler Bursa Efek

15. Fatwa tentang Obligasi Syariah

a. Fatwa No. 32: Obligasi Syariah

b. Fatwa No. 33: Obligasi Syariah Mudharabah

c. Fatwa No. 41: Obligasi Syariah Ijarah

d. Fatwa No. 59: Obligasi Syariah Mudharabah Konversi

16. Fatwa tentang Surat Berharga Negara

a. Fatwa No. 69: Surat Berharga Syariah Negara (SBSN)

b. Fatwa No. 70: Metode Penerbitan Surat Berharga Syariah Negara (SBSN)

c. Fatwa No. 72: Surat Berharga Syariah Negara (SBSN) Ijarah Sale and Lease Back 
d. Fatwa No. 76: Surat Berharga Syariah Negara (SBSN) Ijarah Asset to Be Leased

e. Fatwa No. 94 : Repo Surat Berharga Syariah (SBS) berdasarkan Prinsip Syariah

f. Fatwa No. 95 : Surat Berharga Syariah Negara (SBSN) Wakalah

17. Fatwa tentang Ekspor / Impor
a. Fatwa No. 34: Letter of Credit (L/C) Impor Syariah
b. Fatwa No. 35: Letter of Credit (L/C) Ekspor Syariah
c. Fatwa No. 57: Letter of Credit (L/C) dengan Akad Kafalah bil Ujrah
d. Fatwa No. 60: Penyelesaiann Piutang dalam Ekspor
e. Fatwa No. 61: Penyelesaian Utang dalam Impor

18. Fatwa tentang Multi Level Marketing (MLM)

a. Fatwa No. 75: Penjualan Langsung Berjenjang Syariah (PLBS)

b. Fatwa No. 83: Penjualan Langsung Berjenjang Syariah Jasa Perjalanan Umrah

19. Fatwa tentang Hasil Usaha dalam Lembaga Keuangan Syariah (LKS)
a. Fatwa No. 14: Sistem Distribusi Hasil Usaha dalam LKS
b. Fatwa No. 15: Prinsip Distribusi Hasil Usaha dalam LKS

20. Fatwa tentang Pembiayaan
a. Fatwa No. 29: Pembiayaan Peng-urusan Haji LKS
b. Fatwa No. 30: Pembiayaan Reke-ning Koran Syariah
c. Fatwa No. 44: Pembiayaan Multi-jasa
d. Fatwa No. 45: Line Facility (at-Tashilat as-Saqfiyah)
e. Fatwa No. 89 : Pembiayaan Ulang (Refinancing) Syariah
f. Fatwa No. 91 : Pembiayaan Sindikasi (al-Tamwil al-Mashrifi al-Mujamma')
g. Fatwa No. 92 : Pembiayaan yang disertai Rahn (at-Tamwil al-Maut-suq bi al- Rahn

21. Fatwa tentang Penjaminan

a. Fatwa No. 11: Kafalah

b. Fatwa No. 74: Penjaminan Syariah

22. Fatwa Lain

a. Fatwa No. 10: Wakalah 
b. Fatwa No. 18: Pencadangan Peng-hapusan Aktiva Produktif dalam LKS

c. Fatwa No. 24: Safe Deposit Box

d. Fatwa No. 43: Ganti Rugi (Ta'widh)

e. Fatwa No. 62: Akad Ju'alah

f. Fatwa No. 71: Sale and Lease Back

g. Fatwa No. 77: Jual Beli Emas secara tidak tunai

h. Fatwa No. 82: Perdagangan Komo-diti Berdasarkan Prinsip Syariah di Bursa Komoditi

i. Fatwa No. 85: Janji (Wa'ad) dalam Transaksi Keuangan dan Bisnis Syariah

j. Fatwa No. 86: Hadiah dalam Peng-himpunan Dana Lembaga Keuangan Syariah

k. Fatwa No. 87: Metode Perataan Penghasilan (Income Smoothing) Dana Pihak Ketiga

1. Fatwa No. 88: Pedoman Umum Penyelenggaraan Program Pensiun Berdasarkan Prinsip Syariah

m. Fatwa No. 93: Keperantaraan (wasa-thah) dalam Bisnis Properti

Jumlah fatwa DSN-MUI dapat terus bertambah disesuaikan dengan permintaan fatwa seseorang atau lembaga keuangan syariah terhadap produk-produk baru ekonomi dan keuangan syariah di Indonesia. Para praktisi ekonomi syariah, masyarakat dan pemerintah (regulator) masih terus membutuhkan fatwa-fatwa dari DSN-MUI berkaitan dengan praktik dan produk lembaga perekonomian Islam.

\section{PENUTUP}

Dari uraian di atas dari beberapa pengertian fatwa yang disebutkan oleh para ahli, dapat disimpulkan bahwa kriteria hakikat dan ciri-ciri berfatwa sebagai berikut:

1. Fatwa adalah usaha memberikan penjelasan.

2. Penjelasan yang diberikan itu adalah tentang hukum syara' yang diperoleh melalui hasil ijtihad.

3. Yang memberikan penjelasan itu adalah orang yang ahli dalam bidang yang dijelaskannya itu. 
4. Penjelasan itu diberikan kepada orang yang bertanya yang belum mengetahui hukumnya.

Metode yang digunakan oleh komisi fatwa MUI dalam proses penetapan fatwa melalui 3 pendekatan, yaitu sebagai berikut:

1. Pendekatan qath'i, yaitu pendekatan qath'i dilakukan dengan berpegang dengan nash al-Qur'an dan Hadis untuk sesuatu masalah apabila masa-lah yang ditetapkan terdapat dalam nash al-Qur'an ataupun al-Hadis secara jelas.

2. Pendekatan qauli, yaitu pendekatan dalam proses penetapan fatwa dengan mendasarkannya pada pendapat para imam mazhab dalam kitab-kitab fikih terkemuka (al-kutub al-mu'tabarah). ${ }^{18}$ Pendekatan ini dilakukan apabila jawaban dapat dicukupi oleh pendapat dalam kitab-kitab fikih terkemuka.

3. Pendekatan manhaji, yaitu pendekatan dalam proses penetapan fatwa yang mempergunakan kaidah-kaidah pokok (al-qawaid al-ushuliyyah) dan metodologi yang dikembangkan oleh imam mazhab dalam merumuskan suatu masalah.

Adapun proses penetapan fatwa tentang ekonomi syariah adalah sebagai berikut:

1. Badan Pelaksana Harian DSN-MUI menerima usulan atau pertanyaan hukum mengenai suatu produk lembaga keuangan syariah. Usulan atau pertanyaan hukum ini bisa dilakukan oleh praktisi lembaga perekonomian melalui Dewan Pengawas Syariah atau langsung ditujukan pada sekretariat Badan Pelaksana Harian DSN-MUI.

2. Sekretariat yang dipimpin oleh sekretaris paling lambat satu hari kerja setelah menerima usulan/ pertanyaan harus menyampaikan permasalahan kepada ketua.

3. Ketua Badan Pelaksana Harian DSN-MUI bersama anggota BPH DSN-MUI dan staff ahli selambat-lambatnya 20 hari kerja harus membuat memorandum

\footnotetext{
${ }^{18}$ Mardani, Hukum Ekonomi Syariah di Indonesia (Bandung: PT. Refika Aditama, 2011), h. 222.
} 
khusus yang berisi telaah dan pembahasan terhadap suatu pertanyaan atau usulan hukum tersebut.

4. Ketua Badan Pelaksana Harian DSN-MUI selanjutnya membawa hasil pembahasan ke dalam rapat pleno Dewan Syariah Nasional MUI untuk mendapat pengesahan.

5. Memorandum yang sudah mendapat pengesahan dari rapat pleno DSN-MUI ditetapkan menjadi fatwa DSN-MUI. Fatwa tersebut ditandatangani oleh ketua DSN-MUI (ex officio Ketua Umum MUI) dan sekretaris DSN-MUI (ex officio Sekretaris Umum MUI)

6. Saat ini terdapat 86 fatwa Dewan Syariah Nasional (DSN) Majelis Ulama Indonesia (MUI) mengenai Keuangan dan Perbankan Syariah. Jumlah fatwa tersebut dapat terus ber-tambah disesuaikan dengan permin-taan fatwa seseorang atau lembaga keuangan syariah terhadap produk-produk baru ekonomi dan keuangan syariah di Indonesia.

Format fatwa DSN-MUI hanya terbatas memberikan penentuan status hukum masalah yang difatwakan dan belum bersifat "ifadah 'ilmiah" yakni memberikan kegunaan pencerahan wawasan keilmuan, sehingga kurang memberikan pemahaman kepada kalangan di luar para ulama ekonomi syariah. Oleh sebab itu, disarankan agar setiap fatwa disertai lampirannya, berupa uraian ilmiyah singkat yang mengantarkan pada kesimpulan-kesimpulan isi fatwa. Selain itu, fatwa seharusnya disebarkan oleh MUI kepada masyarakat agar umat mengetahui hukum-hukum ekonomi syariah.

\section{DAFTAR PUSTAKA}

Ali, Zainuddin., Hukum Ekonomi Syariah, Jakarta: Sinar Grafika, 2008.

Amin, Ma'ruf., Fatwa Dalam Sistem Hukum Bank Indonesia, Statistik Perbankan Syari'ah, www.bi.go.id, diakses tanggal 25 November 2015.

Dahlan, Abdul Aziz., et.al., Ensiklopedi Hukum Islam, Jilid I, Jakarta: Ichtiar Baru van Hoeve, 1996.

Depdikbud, Kamus Besar Bahasa Indonesia, Jakarta: Balai Pustaka, 1997. 
Fatah, Rohadi Abdul., Analisis Fatwa Keagamaan dalam Fiqih Islam, Jakarta: PT. Bumi Aksara, 2006.

Hamid, M. Arfin., Ekonomi Syari'ah Sebagai Kebutuhan, Pidato Pengukuhan Guru Besar dalam Bidang Ilmu Hukum pada Fakultas Hukum Universitas Hasanuddin Makassar: Universitas Hasanuddin, 2013.

Mardani, Hukum Ekonomi Syariah di Indonesia, Bandung: PT. Refika Aditama, 2011. Syarifuddin, Amir., Ushul Fiqih, Jakarta: Kencana, 2009

Tim Penyusun, Majalah Peradilan Agama, Edisi III, Mei 2013. 